long as, the kidneys continue to act there is a possibility, even a probability, that the patient may recover; but if albuminuria and suppression of urine occur, and are at all continuous, death will speedily follow. We cannot, however, attribute death from septicamia with suppression of urine after an operation to retention of physiological effete matter which ought to be excreted. As I pointed out in regard to obstruction of the bowels afteran operation, so in this case death is too rapid to be due to the complication alone. Septicæmic suppression of urine rarely lasts more than three days, whereas in simple obstructive suppression of urine life is usually prolonged for from nine to eleven days. ${ }^{16}$ Septicæmic suppression of urine leads, however, to great interference with the circulation of the blood through the kidneys, and thence arises a physiological condition in every respect parallel to that which exists when the blood-flow throngh the mesenteric vessels is interfered with by intestinal distension in cases of obstruction or paralysis of the bowel after laparotomy. It seems to me that death is induced in exactly the same way in both these conditions. There are, therefore, many resem. blances between the two classes of cases, but the only common cause of the exacerbation of the inflammatory fever in septicæmia and in psendo-ileus is the obstruction to the flow of blood through a large and important vascular area. So like, however, are the two modes of death that Olshausen and Verchère, though recognising that there is a difference, have attributed the symptoms of pseudo-ileus to a species of septicrmia peculiar to itself. It may be stated generally that any complication which raises the blood pressure during a traumatic fever is dangerous, and if persistent may induce death in the manner which $I$ have described. Those who do not attribute the changes caused by even the simplest fever to peripheral irritation assert that the phenomena observed are always due to the formation of some poisonous substance, which, circulating in the system, induces the febrile condition. If it be assumed that peripheral irritation is not the cause of fever, both the hypothetical substance which produces this disturbance and its mode of action have yet to be discovered. On the other hand, the views of traumatic fever which I have endeavoured to formulate explain also how certain irritant poisons may cause all the characteristic phenomena of the febrile state. Circulating in the system, these poisons must give rise to a widespread irritation and consequent partial devitalisation of tissue. Such a widespread partial devitalisation of tissue must produce the same effects on the vascular and thermal systems as are brought about by the more obvious devitalisation due to a local irritation. The effect may be slight or so severe as rapidly to induce great contraction of the vessels, a high temperature and death. It is even conceivable that death may be produced almost with the suddenness of shock. In accordance with this we know that in scarlet fever, for example, a fatal result is sometimes brought about before any pathognomonic signs of the disease show themselves. Cholera and certain snake poisons may also kill with extreme rapidity. The peculiarities of the poison, of the individual and of the tissues fully account for the conditions found in the special diseases produced. In every febrile disease there is evidence of peripheral mischief. Sapræmia, septicæmia, pyæmia and all the exanthemata show signs of a widespread irritation with a tendency to inflammation in certain tissues and organs.

Portman-street, $\mathrm{W}$.

\section{A CASE OF REMOVAL OF A PORTION OF THE SIGMOID FLEXURE.}

BY FREDERICK TRTVES, F.R.C.S. ENG., SURGEON TO THE LONDON HOSPITAL.

Wiтhis the last few years surgical literature has become very exuberant in matters relating to the excision of intestine and the union of divided bowel. The long list of "intestinal sutures" has been considerably extended. To many of simple mind it would appear that if two segments of bowel have to be sewn together there is little needed but a suitable needle and cotton and some elementary knowledge of sewing. At the present time, however, this plausible

16 Sir Wm. Roberts : Urinary and Renal Diseases, p. 27. view meets with rebuke, and it is sought to be shown that the union of bowel involves an intricate elaboration of sewing which is far beyond the well practised art of the seamstress. In what may be termed the complexity of minor invention the intestinal suture can now take its place with the pessary and the obstetric forceps. To those to whom even Box's modification of Cox's suture would not appeal there are offered a number of mechanical adjuncts to the process of suturing which are brought forward by clamorous advocates. These include bone plates, gut plates, gut rings, tubes, intestinal bobbins, intestinal buttons and the like. Amongst these appliances Senn's original bone plate is as a Triton amongst minnows. Dr. Senn's invention opened up a new, ingenious and possibly valuable departure in abdominal surgery. Of the many imitations which have followed in its wake the majority are unimportant. Of the value of the bone plate it would be, I imagine, as yet premature to speak. The intestinal clamp, after a brief existence, has passed into the background. It was an instrument for which there was no need. For one of the earliest forms of the clamp I was myself responsible, and although many varieties of the instrument have been invented since that effort $I$ am satisfied to think that my apparatus still remains by far the worst.

I have ventured to publish the following case in order to show that simple measures in uniting bowel may possibly be attended by success and that the older method of operating, so severely condemned by the adrocates of the newest gut plate or bobbin, is not of necessity followed by the death of the patient.

A married woman aged forty-four was sent to the London Hospital on Nor. 27th, 1891, by Mr. Holroyde of Chatham. She had had excellent health until the previous June, when she had an attack of intestinal obstruction. This followed the eating of a considerable quantity of maize and was marked by colic, vomiting, constipation and distension of the abdomen. The patient was well again in fourteen days. A second but milder attack followed in August, 1892, and a third and much severer one in September. Between the attacks the bowels had responded readily to enemata and aperients. 'The symptoms of obstruction had passed away before the patient came to the hospital. On admission she was noted to be of healthy appearance and to be well nourished. The abdomen was soft, pendulous and distended. A very considerable quantity of fæcal matter was evidently lodged in the colon. There was no ascites; no tumour could be detected; a few coils of bowel became occasionally visible; there was no vomiting, and rectal and vaginal examination revealed nothing worthy of note. The treatment consisted of rest, daily massage of the abdomen, the daily use of enemata and aperients and the observance of a carefully selected diet. By these means the abdomen soon regained its normal size, an enormous quantity of fæcal matter was evacuated, the appetite was restored and the patient left the hospital in sixteen days (i.e., on Dec. 13th) expressing herself as feeling quite well. The diagnosis which $\mathbf{I}$ caused to be entered in the notes was "stricture of the large intestine either in the descending colon or sigmoid flexure." No idea of operative interference at this stage was enter tained by the patient. The absence of any of the usual causes of a simple stricture of the bowel led me to suppose that the stricture was due to epithelioma. Nothing more was seen or heard of the patient-who had moved from Mr. Holroyde's district-until Nov. 15th, 1892, when she again entered the hospital. During the year which had elapsed the phenomena of the previous six months had been repeated and intensified. There had been increasing constipation, a more constant use of aperients and more frequent and more severe obstructive attacks. Vomiting was common, the appetite was poor, the patient was haggard and anæmic, had wasted considerably and had become very weak. The abdomen was now greatly distended with ascitic fluid and measured forty-two inches at the level of the umbilicus. Mucl pain was complained of, and vomiting was frequent and troublesome. Aperients merely added to the patient's distress, and enemata produced very little effect upon the now evidently much distended intestine. Rest and opium gave the patient relief and served to prepare her for the operation, which was carried out on Nov. 26th. There was at no time any albumen in the urine. The abdomen was opened through a median incision three inches in length. The ascitic fluid which escaped filled one full-sized bucket. An annular epitheliomatous growth was found on the summit of the 
sigmoid flexure. It presented the usual simple ring, had formed no adhesions to adjacent parts and had not extended beyond the bowel. The abdomen having been freed of all ascitic fluid, the affected loop of bowel was drawn out of the wound and numerous sponges were wedged around it so as to make the operation in every respect extra-abdominal. The growth was found to involve the colon for one inch and a half of its extent; no enlarged glands were detected; the bowel above the stricture was greatly hypertrophied and was so distendedas to equal the adult forearm in circumference. The gut below the stricture was thin, empty and contracted. The colon above and below the part to be excised was clamped by the fingers of my house surgeon, Mr. Speechly. Seven inches of the sigmoid flexure were then cut away with scissors. The contents of this segment were received upon a special sponge. The interior of the bowel was cleaned. A V-shaped portion of the mesocolon was excised with the bowel. This gap in the sigmoid mesentery was at once closed by two sutures of No. 2 silk. The next step was to partly close the divided end of the greatly distended upper segment until the part left patent should correspond to the lumen of the collapsed bowel below. This was done by means of a continuous suture of the mucous membrane, followed by an outer line of Lembert's suture. For each suture No. 1 silk braid was employed, a milliner's needle being used for the continuous suture and a small round Hagedorn's needle for the interrupted stitches. This upper segment of the bowel was as rigid as if made of leather. The two ends of the gut were now joined together in the same way-i.e., by a continuous suture of the mucous membrane and an outer line of Lembert's suture. Whilst I was introducing the interrupted stitches at one end my colleague Mr. Openshaw was inserting them at the other. I should judge that about fifty sutures were employed. The assistant's fingers were now relaxed and the contents of the bowel allowed to pass through. It was apparent that the suture line was at all points water-tight. The sutured bowel was dropped back into the abdomen and the wound in the parietes was closed in the usual way. The operation occupied one hour and a quarter. The patient was sick three times after the operation, and during the convalescence an injection of morphia was given on three occasions only. The highest temperature reached was $101^{\circ}$ on the evening of the second day. The bowels first acted on the third day, when five liquid motions were passed. Between the third and the eighth days the bowels acted twenty-one times. In these motions, which were for the most part liquid, fifteen cherry stones which were swallowed in the previous summer were discovered. The parietal wound was first dressed on the tenth day, when it was found to be soundly healed and all the sutures were removed. On that day the patient was ordered fish. Subsequently to this a slough of mucous membrane containing one of the continuous sutures was discovered in a motion. The patient's recovery was uninterrupted, but her discharge from the hospital was delayed by the tardy healing of a bedsore which had formed before the operation. She returned to the country on Jan. 18th, 1893. She had been up and walking about for some time before this date, but the bedsore had not quite healed when she returned home. The bowels were now acting regularly without aperients; the abdomen was flat; there were no ascites, no pain and no vomiting. The stricture exhibited the ordinary features of cylindrical epithelioma, and the narrowed passage would barely admit a No. 12 catheter.

Wimpole-street, $\mathbf{W}$.

\section{TWO CASES OF AURAL PY EMIA TREATED BY OPERATION.}

BY ALFRED PARKIN, M.S., M.D. LoND., F.R.C.S. ENG., SENIOR ASSISTANT' SURGEON TO THE VICTORIA HOSPITAL, HULL.

Ir is only recently that cases of septic thrombosis of the lateral sinus following ear disease have been successfully treated. Cases are still recorded from time to time which progress to a fatal termination, and it is only by adoption of a radical method, such as that described and so successfully carried out by Mr. W. Arbuthnot Lane, ${ }^{1}$ that such a result can be avoided. The following two cases are good examples

1 Treatment of a case of Pyremia resulting from Disease of the Middle Ear: THE LANCET, Jan. 21st, 1893, Of eight cases so treated Middle Ear: THE
seven recovergd. of the value of ligaturing the internal jugular vein and removing septic matter from the lateral sinus in patients far advanced in pyæmia, whose recovery without interference was, to say the least, most doubteul.

CASA 1.-A child aged nine years was admitted into the Victoria Hospital, Hull, on Dec. 9th, 1892, suffering from great pain in the head and delirium. He had scarlet fever when three years of age, and had had headaches ever since. On Nov. 27th, 1892, he complained of earache on the right side, and during the succeeding nights was said to have been unconscious. On Dec. 1st otorrbca came on, and he was sick once. He had diarrhoa on Dec. 7th and 8th, and he had had several bad attacks of shivering. On admission the patient seemed dull and stupid; he complained of severe pain all over the right side of the head. There was a foul discharge from the right ear, with tender. ness over the mastoid and over the deep ressels of the neck; the tongue was dry and brown, the eyes were jaundiced and the liver was one inch below the ribs and very tender; there were numerous râles at the base of the right lung, with tubular breathing at one spot; both optic discs were swollen, the right more than the left. The evening temperature was $1044^{\circ}$. Under chloroform a curved incision was made behind the right ear and a small collection of pus around the aperture of exit of the mastoid vein confirmed the diagnosis. The antrum was first opened by gouging away half an inch of hard bone; it was found to be full of foul pus, which was cleared away, as well as the contents of the middle ear, and the whole cavity disinfected. The bone bounding the lateral sinus was then gouged away and a quantity of extra-dural pus extending along the lateral sinus groove was removed. The sinus was obviously thrombosed, consequently the internal jugular vein was exposed low down in the neck. The walls of the vein were so thickened by periphlebitis that it resembled more an empty carotid artery than the normal vein. The vein was tied as low down as possible in two places and the piece excised showed numerous flaky deposits on the intima. The cut ends of the vein were disinfected and the wound sewn up. The lateral sinus was then opened up, as much of the clot as possible scraped out, and the cavity treated with perchloride of mercury solution. A drainage-tube was placed in contact with the sinus wall and a second one in the antrum. The next day the headache had gone and the patient's general condition had improved. Convalescence was slow, the lung signs gradually disappeared, the jaundice passed off and the only point of interest in the course of recovery was a rise of temperature to $104^{\circ}$ on Dec. 18th, accompanied by severe headache, with marked œdema of the eyelids, especially on the right side. This seemed to indicate a probable extension of the thrombosis to the right cavernous sinus, but the symptoms subsided gradually along with the temperature. The neck wound and greater part of the mastoid wound healed by primary intention ; and the patient, after being kept under observation until Feb. 15th, 1893, was discharged in excellent health, all wounds healed (very slight mucoid discharge from the right ear), and able to hear ordinary conversation with the affected ear quite well.

CASE 2.-An infant aged eleven months was admitted into the Victoria Hospital on Dec. 12th, 1892. Three months previously she was in the sanatorium for scarlet ferer, and two months afterwards a discharge was first noticed from the left ear, followed in a few days by facial paralysis. She left the sanatorium fourteen days ago, and since then has had several fits, the last a few hours before admission. When admitted the child seemed in a serious condition; she was semi-conscious, her lips were blue, and she called out from time to time, putting her hand up to the left side of her head; the pulse was very rapid; the temperature was subnormal. There was a small swelling behind the left mastoid, about one inch and a half behind the ear, and a foul discharge from the ear itself; the left side of the face was paralysed; bronchial breathing and râles at the base of the left lung were audible; nothing abnormal could be felt in the neck. Under chloroform the small abscess at the back of the mastoid was opened and found to communicate through the foramen of the mastoid vein with the interior of the skull. The antrum was opened and it and the cavity of the middle ear were cleansed of a quantity of foul material. The lateral sinus was exposed and found to be full of broken-down clot, which was all scraped away. The internal jugular vein was then exposed, found empty, and tied; there was no periphlebitis at the point of application of the ligature. The recovery in this case was more rapid than in that of the last patient. The facial paralysis and bronclio- 